\title{
Materiales premonitorios: notas sobre producción cultural, ecología acústica, y tecnologías ancestrales
}

\author{
Materiais premonitórios: notas sobre produção \\ cultural, ecologia acústica e tecnologias ancestrais
}

\section{Premonitory Materials: Notes on Cultural Production, Acoustic Ecology, and Ancestral Technologies}

Jorge Bejarano Barco *

http://dx.doi.org/10.22409/poiesis.2033.121-144

RESUMEN: Este artículo reúne algunas iniciativas en las que el autor ha participado como artista, educador y curador entorno al sonido y las tecnologías ancestrales. Aborda de forma experimental su interrelación e implicaciones con el arte, la producción cultural, los museos y laboratorios en la actualidad.

PALABRAS CLAVE: Yagé; maloka; curaduría; ecología acústica; tecnologías ancestrales

\footnotetext{
“ Jorge Bejarano Barco é artista, curador e produtor cultural. É curador de Projetos Especiais do Museu de Arte Moderna de Medellín, Colômbia, e bacharel em Ciências Sociais pela UDFJC, Bogotá, com pós-graduação em Gestão Cultural e Patrimônio na Fundação Ortega y Gasset, Buenos Aires, Argentina. Atualmente cursa o mestrado em Arte Sonora na Universidade de Barcelona, Espanha. E-mail: jorge.bejarano@mammedellin.org
} 
RESUMO: Este artigo reúne algumas iniciativas nas quais o autor participou como artista, educador e curador em torno do som e das tecnologias ancestrais. Aborda de forma experimental sua interrelação e implicações com a arte, com a produção cultural, os museus e laboratórios hoje.

PALAVRAS-CHAVE: Yagé; maloca; curadoria; ecologia acústica; tecnologias ancestrais

ABSTRACT: This article brings together some initiatives in which the author has participated as an artist, educator and curator around sound and ancestral technologies. It deals experimentally with its interrelation and implications with art, cultural production, museums and laboratories today.

KEYWORDS: Yagé; maloka; curatorship; acoustic ecology; ancestral technologies

Como citar: BARCO, Jorge Bejarano. Materiales premonitorios: notas sobre producción cultural, ecología acústica, y tecnologías ancestrales. Poiésis, Niterói, v. 20, n. 33, p. 121-144, jan./jun. 2019.

doi: http://dx.doi.org/10.22409/poiesis.2033.121-144

Poiésis, Niterói, v. 20, n. 33, jan./jun. 2019. 


\section{Materiales premonitorios: notas sobre producción cultural, ecología acústica, y tecnologías ancestrales}

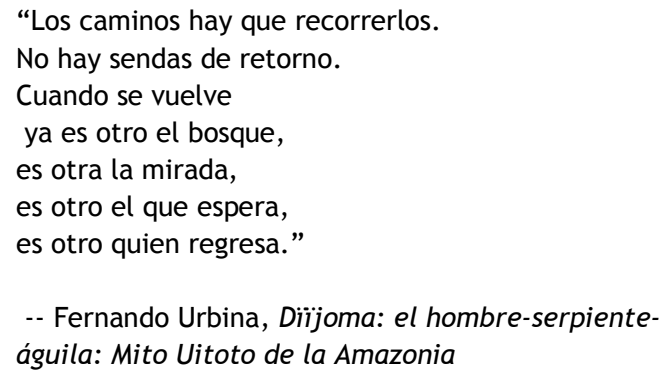

La idea de hacer conscientes las prácticas y saberes intuitivos, cruces ontológicos y epistémicos, de explorar imaginarios experimentales, otros sistemas de percepción...las grietas como un primer paso hacia un giro ético y de producción de pensamiento motivan estas notas. 
La invitación a escribir en torno a las posibles perspectivas del binario escuela/bosque desde una mirada experimental me ha hecho reunir algunas ideas e iniciativas en las que he participado durante los últimos años como artista, educador y curador, y en este camino de la memoria y el pensamiento me he hecho consciente de la conexión que les une. Como en los icebergs, nuestros ojos se acostumbran a ver sólo la pequeña parte del objeto que sobresale, pero debajo permanece oculto aquello que es fundamental y le mantiene a flote; solo escuchando profundo logramos comprender el ecosistema completo. Así, he seleccionado una serie de proyectos, ideas y acciones vinculadas con el verde del bosque y el sonido, y he encontrado que tienen una raíz común: el bejuco del Yagé (Banisteriopsis caapi), y el mundo de la Maloka. Ha sido el contacto ceremonial con estas tecnologías ancestrales y lo que les rodea, un motor para crear visiones, entrelazar los pensamientos y conectarlos con la red de la vida. Ahora estos proyectos e ideas se conectan y se enraízan, haciendo que germinen nuevas ideas para seguir creciendo como un bosque en los tiempos que vienen.

Con la naturaleza como la manifestación visible del espíritu, empezar así a bosquejar un escrito militante que logré sacar de adentro aquello que me atraviesa en este momento; que funcione como una máquina desde la cual conectar la acción-pensante y el pensamiento-actuante. Un espacio temporal de reflexión y experimentación, táctica de resistencia y agenciamiento de la ética, la estética y la política.

Poiésis, Niterói, v. 20, n. 33, jan./jun. 2019. 


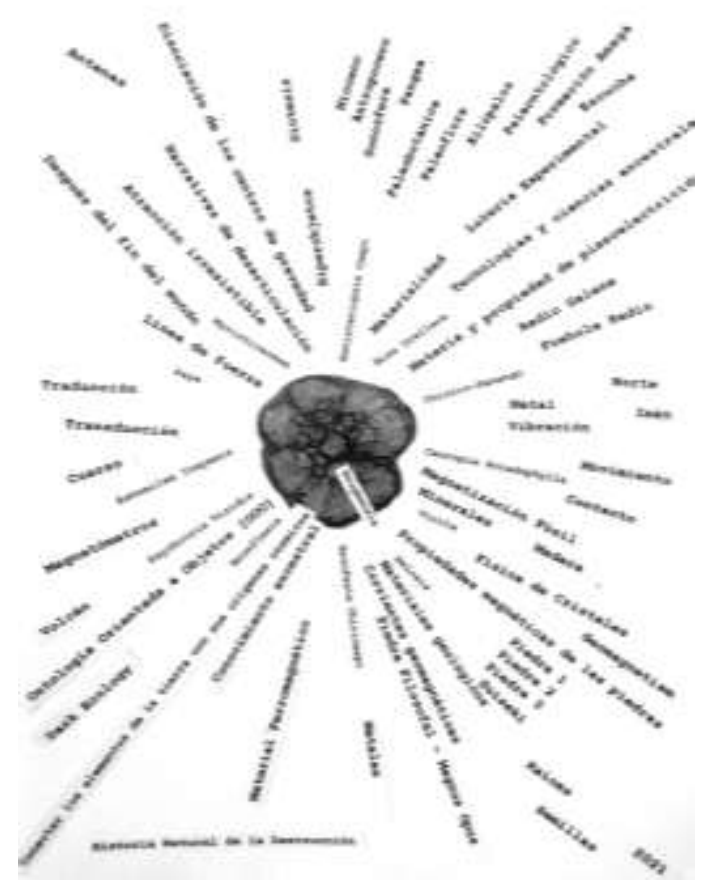

Fig. 1 - Jorge Bejarano Barco, Materiales Premonitorios: geología especulativa (collage), 2018. mapa mental inspirado en un corte transversal de bejuco de Yagé. 


\section{El mundo es un maloka}

La primera imagen que vino a mi mente al pensar en el tema de esta revista fue la Maloka como lugar de encuentro y de escucha del mundo, un lugar que nos invita a conectarnos con la red de la vida, donde todos - plantas, animales, seres humanos, seres celestes (planetas, sol, luna, estrellas) y espíritus - somos uno.

La Maloka o Casa del hombre es la forma tradicional de vivienda de los grupos indígenas en el Amazonas, y actúa como centro ritual y lugar sagrado para estas comunidades. Se construye a partir del conocimiento y sabiduría de la cultura indígena. Es el lugar de reuniones, de congregación y de aprendizaje. En el pensamiento indígena la primera Maloka es la Tierra, pues es la gran casa donde vivimos todos. La mayoría de las cosmologías coinciden en que su construcción representa un intento por definir un espacio propio a partir del cual el hombre pueda manejar el mundo pasando del caos, al orden, al cosmos.

La Maloka es la combinación de arquitectura social y arquitectura sagrada que varía en su forma de fabricación según el grupo indígena o la etnia que la realice. Se fabrica con materiales de la región donde se realiza -en especial madera y palmas-. Las formas utilizadas son la circular, ovalada o rectangular, que pueden hacerse en distintos tamaños. Allí se deposita la tradición y los conocimientos de los antepasados; desde ella se dicta el buen manejo del territorio, el equilibrio entre las acciones de los seres humanos, espirituales y el entorno natural del que son parte.

En el año 2014 con motivo del Foro Urbano Mundial (WUF) que se realizó en Medellín, fuimos invitados a proponer el salón para llevar a cabo las reuniones del grupo de Naciones Unidas. Gracias la amistad con la familia Giagrekudo, pertenecientes a la comunidad Uitoto (murui-muinane-) de la Amazonía Colombiana, logramos construir una Maloka dentro del principal recinto de exposiciones de la ciudad. Su construcción fue precedida de la ritualidad necesaria y se convocaron además a líderes de otras etnias del país a contribuir con su palabra y sus manos. Allí se llevaron a cabo las conversaciones de los líderes de las políticas públicas en torno al crecimiento de las ciudades en el mundo, para nosotros poner la Maloka allí representaba una lección de humildad, una invitación a la palabra, a

Poiésis, Niterói, v. 20, n. 33, jan./jun. 2019. 
la escucha y a generar acuerdos necesarios para vivir mejor en el planeta. Al final del encuentro, todos los recursos usados en esta gran Maloka fueron trasladados para ser reutilizados en construcción de una nueva Maloka en las montañas de Medellín, allí nos reunimos ahora diferentes grupos de personas para escuchar a los conocedores de la cosmología indígena, especialmente a chamanes y abuelos sabios de varias de las etnias del sur de Colombia.

Para ellos la Maloka es considerada la casa madre, la representación de la vida misma, de la unidad, pues invita al encuentro de la comunidad. Es un espacio para la creación y la circulación del conocimiento espiritual y terrenal donde se da consejo y se transmite la tradición, las creencias, roles y oficios. Pero también se sana el cuerpo, la mente y el espíritu de los miembros de la comunidad, de la tierra y el universo.

Con el tiempo van surgiendo nuevas Malokas por fuera de la selva. En la zona rural del municipio de Santa Rosa de Cabal, en el Eje Cafetero Colombiano, está Minka Lab, un proyecto agro-cultural que fue fundado en 2014 por un grupo de artistas y activistas ambientales de Colombia, Alemania y Francia. Dedicado a cultivar espacios donde los grupos indígenas locales, los pequeños agricultores y grupos afrocolombianos puedan resistir el aislamiento y la marginación a través del desarrollo de prácticas agroecológicas sostenibles que no sólo revitalizan la tierra, sino que recuperan la cultura y fortalecen la comunidad. Un punto de encuentro para la experimentación con el medio ambiente, el arte y la tecnología, así como con los rituales tradicionales y la medicina holística. En su Maloka, que allí tiene la forma de Domo Geodésico, recientemente realizamos el encuentro Conectando Antenas con raíces; una reunión de artistas electrónicos que hoy integran elementos de cosmovisión indígena en su práctica. 


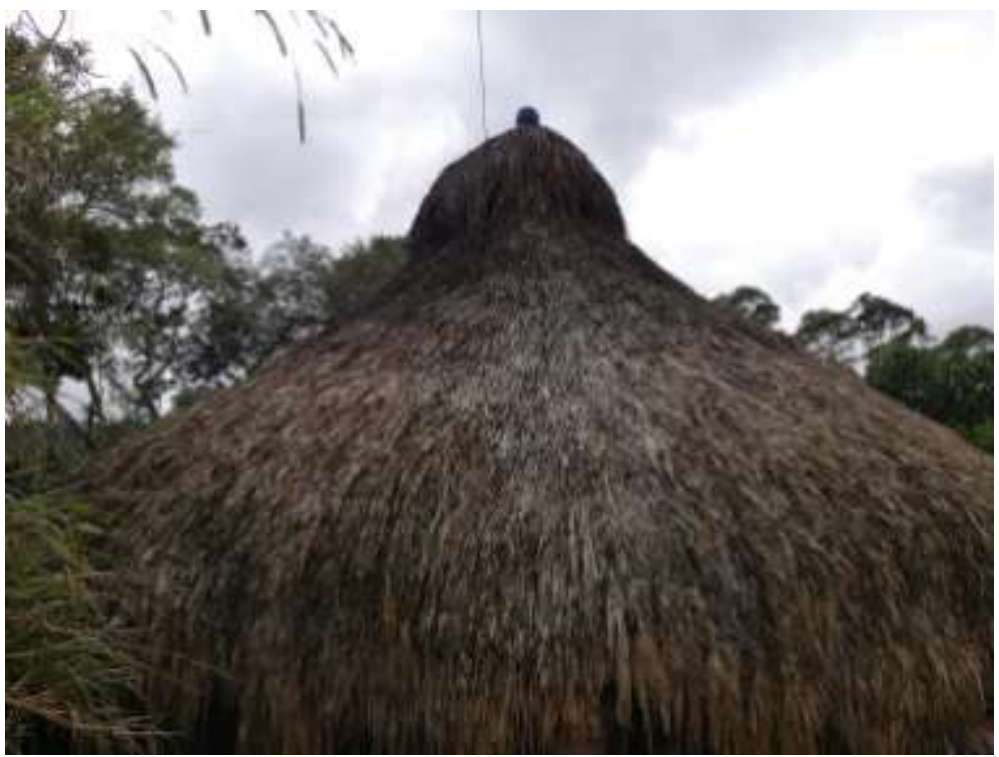

Fig. 2 - Maloka en el corregimiento de Santa Elena, Departamento de Antioquia, Colombia (detalle). (Foto: Jorge Barco. 2018)

Poiésis, Niterói, v. 20, n. 33, jan./jun. 2019. 


\section{Banisteriopsis Caapi (Yagé)}

"Las plantas sagradas han tenido en la historia de la humanidad un papel más destacado de lo que inicialmente sugería el conocimiento común. Las culturas de tradición oral muestran su admiración hacia estos vegetales tan especiales a través de sus formas de nombrarlas: semen del sol, enredadera de las serpientes, pilar del cielo, planta de la adivinación o carne de los dioses." (SCHULTES Y HOFFMAN, 1993, p. 3)

Los saberes que han acumulado por años los pueblos indígenas están enfocados en resguardar el equilibrio del cosmos. Por eso tenemos mucho que aprender de su arquitectura, formas de organización, relacionamiento social y medicina, pues su conexión con la naturaleza en un sentido de ecosistema les permite vivir en armonía con los otros que ahí habitan.

En la investigación de la conciencia cada persona puede sumergirse en la profundidad de su inconsciente para develar el origen y existen tecnologías ancestrales para emprender este camino. En la medicina tradicional del Putumayo colombiano encontramos una de las plantas visionarias más importantes de la Amazonía: la ayahuasca, la enredadera que crece formando una doble hélice y cuyo nombre también puede ser traducido como: 'bejuco del alma', 'bejuco de la iluminación', 'bejuco de la visión', o 'bejuco del discernimiento', y la cual - en una preparación con otras plantas - brinda una experiencia ontogénica catártica, liberadora y de exploración de la conciencia de la cual hemos participado en esta Maloka.

"Un bejuco continuo que se extiende hasta el principio de los tiempos... y que se lo compara con un cordón umbilical que vincula a los seres humanos con el pasado mítico." (SCHULTES, 2004, p. 33)

Esta potencia de la naturaleza y el bosque como generadores de nuevas conectividades y colectividades, como instrumento de síntesis y de visión multifocal orienta estas ideas, les da fuerza y forma. Síntesis como combinación de cosas y procesos que crean otros nuevos.

El Yagé, la Maloka y la cosmovisión indígena contienen las herramientas y el conocimiento necesario para ayudar a superar el apocalipsis ecológico y encaminar a la humanidad por una senda diferente en este momento. 


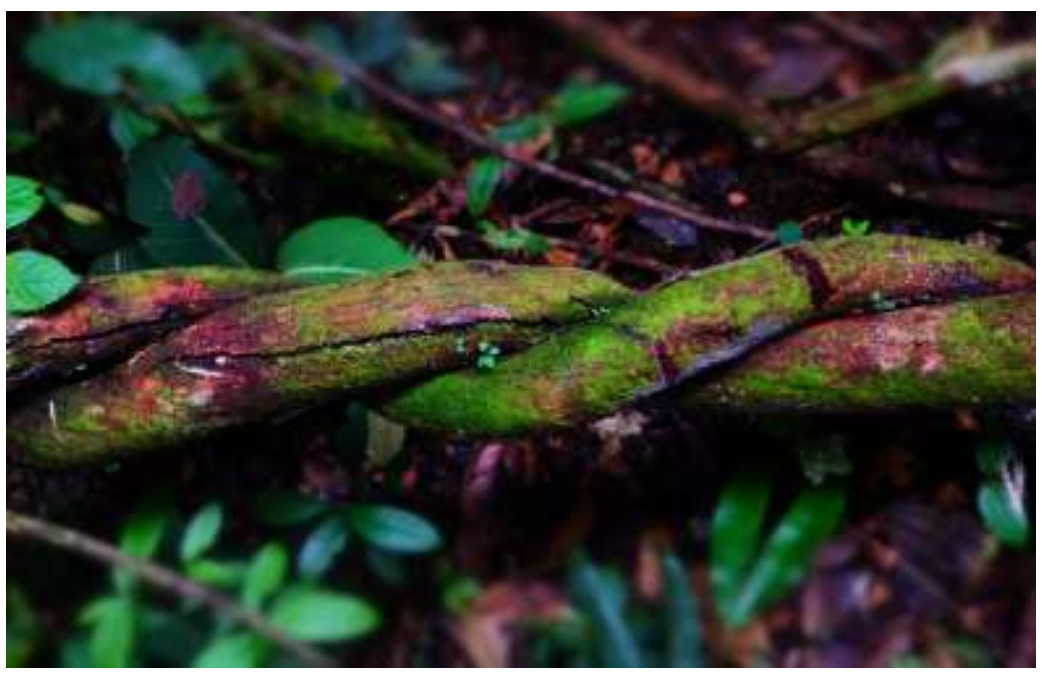

Fig. 3 - Aghia Sophie. Vereda Eslabón en Mocoa Putumayo, Colombia, abril de 2019. (Cortesía de la artista)

Poiésis, Niterói, v. 20, n. 33, jan./jun. 2019. 


\section{Islas y archipiélagos y escritura Mangle}

A nivel formal este texto explora la interrelación entre islas, archipiélagos y manglares con otros elementos de la naturaleza que son tomados como metáforas; un conjunto de notas, aforismos, citas... de escritura nómada e hipertextual para ir asociando entre sí como un collage, como un follaje.

Una isla es una zona de masa terrestre estable rodeada por una masa de agua. Un archipiélago es el conjunto de islas agrupadas en una superficie del mar. Los archipiélagos más frecuentes son aquellos de naturaleza volcánica asociados a grandes erupciones de magma. Dependiendo del origen geológico, las islas y los archipiélagos pueden ser oceánicos o continentales. Además de islas, los archipiélagos pueden contener otras masas de tierra menores como islotes, arrecifes y cayos. Cada párrafo escrito aquí puede encontrar su correspondencia en estas formaciones geológicas, y su estructura general se asemeja a un Manglar.

Quizás otra forma de decir escritura mangle sería evocar el rizoma de Deleuze, pero ahora busco tropicalizar los conceptos como estrategia decolonial. ¿Puede existir una escritura en forma de manglar?

"Contemplar un manglar es adentrarse en nuestro propio interior; líneas, rectas, cuevas, caos, ilusión, vida, grandeza parecen mezclarse en esa intrincada red que a simple vista parece caos, pero una vez nos adentramos, vemos con fascinación que cada parte es una expresión, un reflejo de nuestra propia realidad. Al crecer, ésta se sube hacia el cielo, con ímpetu de grandeza, como queriendo dejar a su madre tierra. Mas, pasado cierto tiempo, como si cayera en la cuenta de su absoluta dependencia de su contorno, traza hilos, trenza fuerza, busca soporte, busca sus raíces a través de sus propias raíces". (ABDALA Y SUÁREZ, 2015)

Nadie puede escribir sin imaginar un paisaje, el paisaje que intentó bosquejar contiene estos elementos. Una posible ruta para recorrerlo emana del magma volcánico que está 
en el centro de la tierra hasta formar una isla, recorre muchas islas, un archipiélago, un manglar, un río.

\section{Magma volcánico}

Recientemente en el encuentro Minka Lab. (2019) mientras contemplábamos sentados el fuego en la Maloka, un fuerte temblor de tierra nos estremeció, de esta experiencia surgió este poema:

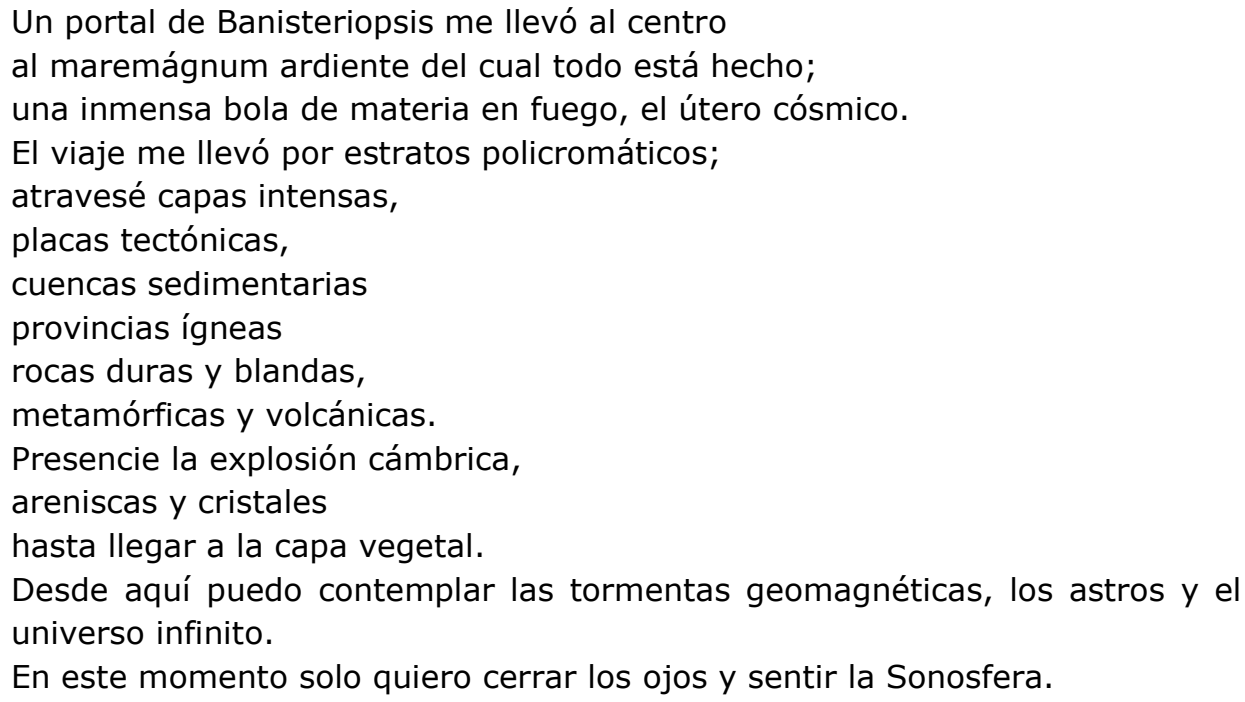

En este momento solo quiero cerrar los ojos y sentir la Sonosfera.

\section{Sonosfera y ecología acústica}

En el intento de descifrar el pensamiento humano a partir del sonido, surge el concepto de ecología acústica como una suerte de existencia en la que predomina la escucha del propio ser, unida tanto al territorio como al momento en el que el hombre interactúa con el espacio sonoro. Al acercarnos a la ecología mental entendemos que dicha forma de estar en el mundo a través de la escucha atenta está relacionada con la ecología acústica de

Poiésis, Niterói, v. 20, n. 33, jan./jun. 2019. 
la tierra, la cual abre la posibilidad de una travesía sonora; una travesía del conocimiento y reconocimiento de la tierra misma.

Pauline Oliveros - una de las figuras centrales de la música experimental y la electrónica empleó la palabra Sonosfera por primera vez a finales de la década de los sesenta. definió así a la atmósfera compuesta por diferentes ondas que emanan desde el centro de la tierra; un barrido completo de energías que incluyen magnetismo eléctrico, electromagnetismo, geomagnetismo, ondas cuánticas como acústicas, resonando en lo personal, interpersonal, musical, la tierra y el cosmos en escalas físicas y metafísicas, a diferencia del paisaje sonoro no hay un estigma moral diferenciando lo tecnológico y lo natural. Va aún mucho más profundo. la Sonosfera no son solo ondas, también está construida por partículas de energía (phonones). (KAHN. 2013, p. 150)

\section{Escucha Y Arte Sonoro}

Las prácticas artísticas vinculadas al sonido han abierto múltiples caminos para la creatividad, el cuestionamiento de paradigmas y la expansión de los lenguajes del arte contemporáneo. La reivindicación del sonido como un aparato autónomo con potencia transformadora se ve reflejada en el creciente interés de muchos artistas y profesionales de otras disciplinas. museos, galerías, eventos de arte y plataformas que abren espacios para la difusión de proyectos en los cuales el sonido ocupa un lugar central, así como un público receptivo participando y auto formándose en la escucha por medio de exposiciones, actos en vivo, entornos interactivos y publicaciones dan cuenta de ello.

Varias de las siguientes ideas emanan de mi trabajo entorno la sala de experimentación sonora (Lab3) del Museo de Arte Moderno de Medellín (MAMM). Temas, procesos artísticos y preguntas que han surgido a partir del trabajo de curaduría y gestión de exposiciones, actos en vivo, talleres y proyectos especiales en este espacio. 


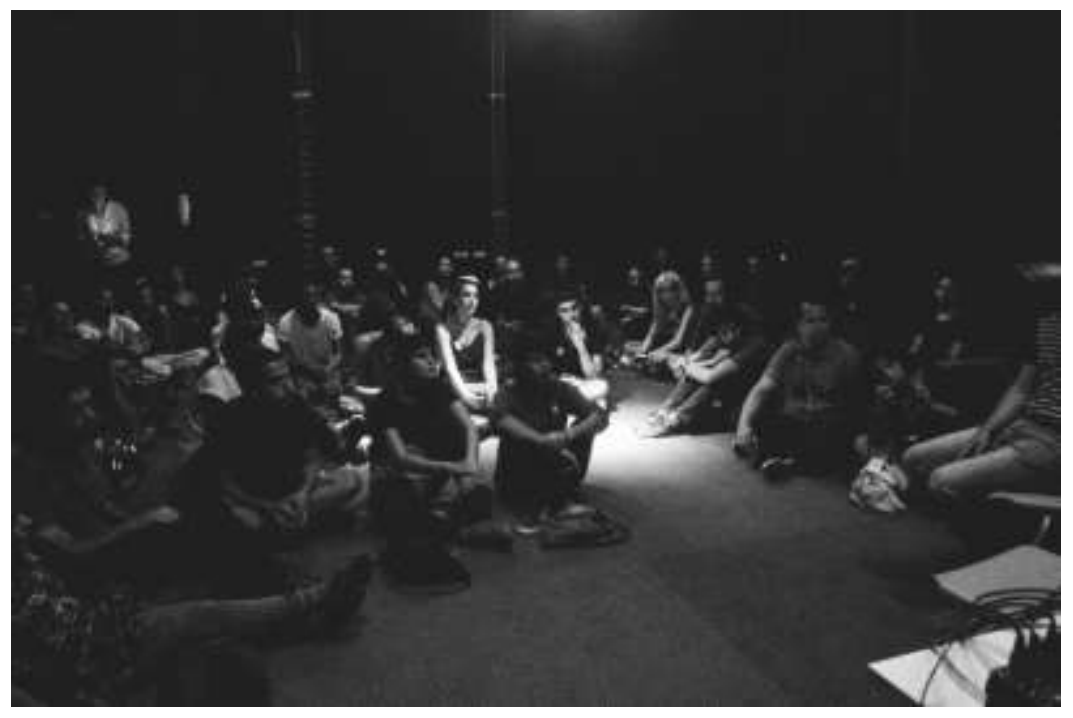

Fig. 4 - Sesión de escucha profunda en la Sala de Experimentación Sonora - Lab3, 2016 (Foto: Yohan López. Cortesía MAMM)

Poiésis, Niterói, v. 20, n. 33, jan./jun. 2019. 
Nociones como paisaje sonoro, ecología acústica, acusmática, escultura sonora, silencio, escucha profunda, ruido, electroacústica, cartografías sonoras, poesía sonora, radio arte, computer music, circuit bending, tecnologías mestizas, tecnochamanismo, meditación, mediación, cultura hacker, paisaje electromagnético, sonosfera y un amplio listado de prácticas y conceptos han entrado a formar parte de mi léxico creativo a partir de la labor de curador de sonido de este espacio y están inspirando hoy nuevas perspectivas de creación.

Desde el año 2009 se empezamos a realizar en el Museo, iniciativas en torno al cruce entre arte, ciencia, tecnología y comunidades que tomaron forma en varios encuentros y proyectos. En el año 2011 hubo una gran confluencia de artistas y masa crítica entorno al Primer Encuentro Internacional de Laboratorios de Medios (LabSurLab), un encuentro en el que se conformó una red de trabajo con artistas y activistas de varios espacios de Iberoamérica y que significó - entre otras cosas - la irrupción del Ruido en el espacio del Museo; talleres y laboratorios exposiciones y eventos performaticos con sonido abrieron las posibilidades de trabajo con metodologías de los laboratorios experimentales, los modos de hacer de la cultura hacker y la colaboración con colectivos independientes y la reflexión crítica sobre las tecnologías.

A partir del año 2015 con la expansión del Museo la apuesta por las artes electrónicas y la cultura digital se fue decantando hacia el sonido, y para ello se crea la Sala de Experimentación Sonora, (Lab3) como un espacio para la investigación y creación de los procesos artísticos que incorporan el sonido como elemento primordial, que reflexionan sobre las diferentes formas de escucha y críticamente sobre la tecnología, que involucran la pedagogía, la ecología y el trabajo con comunidad.

A continuación, reseño algunas de las exposiciones que hemos realizado en la Sala de Experimentación sonora vinculadas a la noción de naturaleza. 


\section{Selva lluviosa}

En el año 2018 realizamos la exposición Hyper-Rainforest del artista español Francisco López, una instalación sonora inmersiva creada a partir de grabaciones ambientales originales de la densa vegetación de selvas y bosques tropicales lluviosos de Australia, Argentina, Brasil, Costa Rica, Cuba, Gambia, Japón, México, Nueva Zelanda, Sudáfrica y Venezuela. Lugares donde se despliega un mundo naturalmente acusmático, en los que es posible escuchar sin que sus causas sean visibles. Su exposición a manera de composición acusmática en un bucle de 40 minutos no intentó reproducir la realidad natural y original de los lugares, sino recrear la hiper-realidad (un mundo sonoro virtual auto-suficiente), que indaga en la dimensión trascendental de la materia sónica misma, lo cual conlleva una interpretación ontológica, existencial y espiritual de la escucha profunda.

\section{Darién}

La región del Darién es un área ubicada en el límite de Centroamérica y Sudamérica que ha funcionado históricamente como una barrera natural entre ambos subcontinentes. Por varios años, el artista David Escallón (Medellín,1990) ha visitado esta región y registrado allí sonidos que son el insumo principal de esta instalación. En ella presenta múltiples reflexiones sobre la relación entre el ser humano y la naturaleza que lo rodea en una sucesión de sombras y silencios, de ráfagas y microsonidos, de cromatismos, atmósferas invisibles y ondas. Una ondulación que alterna las manifestaciones temporales y espaciales que le son propias al Darién colombiano: de la zona oceánica a la selva espesa, de lo macro a lo micro, del día a la noche. Un bucle que contiene elementos de este ecosistema en su devenir natural, ondas que deambulan entre canales de sonido, proyectores de video, mosaicos de espejos y gotas de agua, los cuales ofrecen un refugio en la imaginación para que cada quien construya su propia selva.

Poiésis, Niterói, v. 20, n. 33, jan./jun. 2019. 


\section{Territorio táctil}

El proyecto con el cual se abrió el Lab3 en el año 2015. Un laboratorio- instalación comisionada al artista Carlos Gómez Caballero basó su razón de ser en una reflexión sobre la idea de interfaz, así de la cartografía como acercamiento directo al territorio y al paisaje. Se trabajó en el registro de paisajes sonoros con un grupo de jóvenes de diferentes disciplinas bajo el formato de laboratorio, en un perímetro cuyo centro fue el Museo. Fueron días intensos de experimentación, recorridos urbanos y de construcción colectiva de conocimiento. El proyecto reivindicó diversas formas de percepción no visual a la vez que otorgó un carácter plástico y maleable al sonido. Territorio táctil propuso un espacio para el disfrute y la escucha atenta. Una interfaz táctil -bordada a mano por los jóvenes participantes- que respondía al roce de las manos; un lienzo convertido en membrana sensible al tacto que al tener dibujado un mapa, alimentaba y esculpía en el espacio los sonidos del territorio representado.

\section{Jaguiey y cuerpos de agua}

El nombre de esta instalación sonora del artista Leonel Vásquez tomó como referencia los jagüeyes naturales de la Guajira; grandes depresiones donde se empoza el agua que escurre sobre la superficie y se estanca por la acción contenedora de las tierras arcillosas. Desde el pasado, la comunidad Wayuu se ha servido de estos recipientes para recibir y acumular las aguas de lluvia durante las épocas de invierno y abastecerse en las de sequía. Estos recipientes geofísicos son muestra de resistencia, adaptación y coexistencia de múltiples formas de vida sometida a ecosistemas extremos.

El proyecto presentado en el Lab3 estuvo articulado a partir de tres núcleos 1. Cuerpos de agua, en la que se invita a explorar las posibilidades de sentir el sonido con los huesos, la piel y los fluidos internos. 2. Supervivencia, hacia el encuentro de las voces, los cantos y sonidos que pueblan las aguas: ecos y resonancias del paisaje sonoro y el encuentro con las tradiciones culturales en las que el canto configura el territorio. Y Por último 3. Reservorio, nos invita a pensar la catástrofe ambiental desde la perspectiva de las memorias de los paisajes sonoros en extinción. 


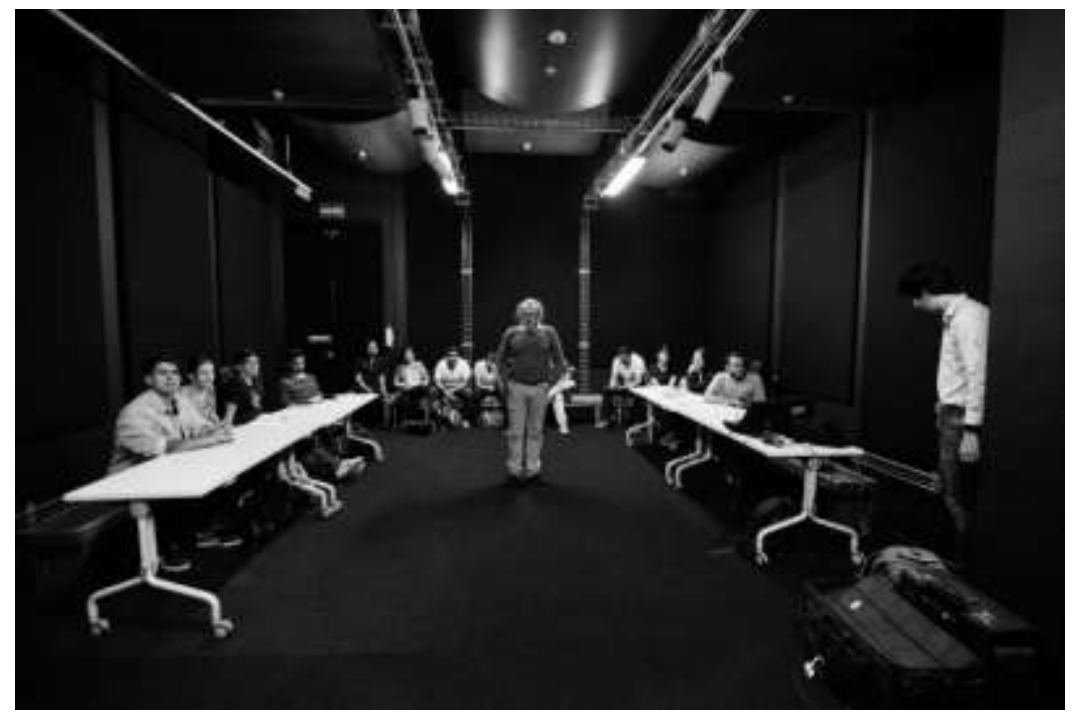

Fig. 5 - El artista y docente Roberto García desarrollando un laboratorio de espacialización en el Lab 3 en el marco de la Semana de la Escucha, 2017. (Foto: Yohan López. Cortesía MAMM)

Poiésis, Niterói, v. 20, n. 33, jan./jun. 2019. 
El agua del jagüey, aparte de tener una función de supervivencia para el consumo humano, para bañarse y para dar de beber a los rebaños de cabras etc., también tiene un lugar importante en la tradiciones y costumbres de los pueblos de la Guajira. El agua en este entorno configura el paisaje; los Jagüeyes son nodos palpables de un tejido de relaciones biológicas y culturales donde se despliega lo humano, lo natural y lo sobrenatural. El Jagüey es reservorio de agua, reservorio de sonidos, reservorio de vida.

En los jagüeyes se deposita la posibilidad de subsistencia de una población que en los últimos años se ha visto en riesgo por la larga temporada de sequía, por lo tanto, se han intensificado los desplazamientos y una incesante activación de la comunidad entorno a ceremonias en las que se cantan jayechies para llamar la lluvia.

\section{Cecropia peltata}

En la exposición Yarumo, diálogos y resonancias el artista Daniel Lara Ballesteros interpretó las vibraciones que emanan de los árboles de Yarumo (Cecropia Peltata) muy comunes en el departamento de Antioquia, con el objeto de trasladar y propagar dichas frecuencias a través de una plataforma de madera para que el público, sentado o acostado, perciba la vibración y sonoridad de manera íntima.

Este trabajo conlleva un propósito terapéutico ya que el yarumo posee propiedades como antiasmático, como medio eficaz en lo que refiere a la movilidad nerviosa del cuerpo, en la ampliación de la capacidad sensorial, y como regulador de las funciones del corazón. De acuerdo con las costumbres indígenas de ciertas zonas de Colombia su hoja, triturada y cocida, es uno de los elementos propios de la preparación del mambe, cuya elaboración tiene entre otros fines estimular el don de la palabra.

Yarumo. Diálogos y resonancias buscó generar, a partir de la comunicación que el artista establece con los yarumos y por medio de vibraciones sonoras, sensaciones que permitan percibir o sentir, al tacto y al oído, la paz, belleza y energía armónica que estos árboles transmiten cuando se está en su cercanía. 


\section{Micro-ritmos, mensajes bioeléctricos de Medellín}

Para este proyecto el colectivo Interspecifics conformado por Leslie García y Paloma López realizó un laboratorio de investigación y creación con un grupo de participantes que recolectó muestras de tierras de distintas áreas de Medellín con el objeto de alimentar celdas bacterianas y producir por este camino energía bioeléctrica. Así, los procesos producidos por las piezas durante la exhibición se encontraban ligados a la geografía de la ciudad. Se creó una instalación que amplifica el micro voltaje producido por estos organismos microscópicos y transduce sus oscilaciones en señales electrónicas puras con las cuales crean un sistema audiovisual que evoca los orígenes de los lenguajes codificados. un mundo híbrido con sonidos y movimientos lumínicos provenientes de la energía generada por bacterias, entendido como un sistema interespecies. Micro-ritmos es un proyecto que se inscribe en el campo del bioarte, acude a las metodologías propias del formato laboratorio, y experimenta sobre la comunicación entre especies. En este proyecto, el concepto de interfaz emerge como un vinculador entre mundos, un puente comunicante que sensibiliza y nos invita a observar y escuchar más allá de lo que nuestros sentidos nos permiten.

Este proyecto se creó a partir de conocimientos entrelazados, en los que conviven de forma horizontal la tecnología, la ciencia y el arte para crear nuevas aproximaciones a la realidad. No es solo el ser humano quien observa y comunica el estado del mundo; otros, en este caso las bacterias, perciben desde su particular interfaz sensorial y responden creando una compleja red de bioelectricidad y vibración, en un performance expresivo del entorno y sus habitantes.

\section{Rarae aves}

En el amplio espectro de las artes sonoras y electrónicas, algunos artistas y creadores se han interesado por la experimentación sonora con el espectro electromagnético y la radio a partir de prácticas de código abierto y software libre, introduciendo alternativas estéticas y tecnológicas en la creación de artefactos híbridos en los que se combinan los len-

Poiésis, Niterói, v. 20, n. 33, jan./jun. 2019. 
guajes de la ciencia, el arte y las tecnologías desde una perspectiva crítica, especulativa e inestable.

En Rarae Aves (2017), el artista Alejandro Duque trabajó con captura de señales en tiempo real - desde pasos de satélites a la voz de la radio de los taxistas en frecuencias piratas, entre muchas otras fuentes posibles que hacen parte de ese paisaje sonoro invisible. El espacio del Lab3 se convirtió en un instrumento en el que se cruzaron nociones pseudo-científicas y especulación popular con dispositivos para el análisis científico; desde plantas de cactus expuestas a contaminaciones de electrosmog hasta una Caja de Faraday resonante.

Rarae aves fue un proyecto que exploró el paisaje sonoro inaudible que afecta a los seres humanos, por medio de la captación y manipulación de ondas y campos electromagnéticos a través de antenas dispuestas en el Lab 3 y en las terrazas del Museo, generando una mezcla de tiempos y espacios cambiantes durante el transcurso de la exposición. Los visitantes se sumergían así en una metáfora de la Torre de Babel en la que fue posible escuchar el ruido del mundo y reflexionar sobre sus implicaciones políticas, sociales y ecológicas.

\section{Edunoise}

Un ámbito pertinente de investigación acorde con estas prácticas sonoras está en elaborar metodologías de trabajo que vinculen el sonido desde perspectivas experimentales con la educación; sonido en un sentido amplio, lo cual incluye incluso de ruido. Para ir cerrando este listado de ideas, voy referirme a una experiencia autogestionada en la que participé recientemente.

En el año 2015 junto a dos colegas arte educadores de Madrid, (Patricia Raijenstein y Selu Herraiz) creamos un colectivo Ilamado Edunoise. Un ámbito de investigación y experimentación para el diseño de artefactos educativos basados en la escucha activa y la producción de ruido. Los principios, manifiesto Edunoise fueron: 
la Educación. Entendida como proceso participativo; acción y reflexión; un espacio-tiempo en el que la presencia activa de cada miembro y su experiencia vital es fundamental para el desarrollo de un conocimiento conjunto; un cuerpo mutante que se transforma según los intereses y aportaciones del grupo que participa.

El Ruido (Noise). Físicamente como la interferencia, la variación, el fallo. Y metafóricamente como la alteración de los sentidos, el valor de lo no controlado, la irrupción del pensamiento divergente, la activación de lo creativo y del acto mágico, el cortocircuito de la razón y la apertura a la imaginación, al azar y la sorpresa. Edunoise quiere ser una señal de ruido en la melodía del conocimiento.

La Escucha Activa. Una forma creativa y participativa de escuchar el mundo para conocerlo mejor y de escucharse a uno mismo para conocerse mejor. En un mundo hipervisual, quizás sea el momento de escucharnos más.

El Cacharreo - Guambiara. (Do It Yourself, Hazlo Tú Mismo) como forma de empoderarse en el uso de la baja-tecnología (low tech), destripando lo que no se destripa, jugando, experimentando, fallando... tocar donde dice 'no tocar', soldar y des-soldar, montar, probar, desmontar ... hasta construir nuestros propios objetos sonoros. La desmitificación de la tecnología.

El Pensamiento Mágico, el Acto Poético y el Juego para desarrollar sistemas de pensamiento alternativos al estrictamente racional y generar simbologías que nos permiten imaginar posibles futuros, diversos modos de ser o diferentes maneras de relacionarnos y expresarnos. Distanciado de la religión o el fanatismo espiritual, se acerca a la poesía, al pensamiento artístico, donde la analogía y la metáfora sirven para explicar cosas que suceden, que se sienten, pero que el lenguaje racional ha invisibilizado.

\section{Manifiesto Edunoise}

- Hacer es pensar

- El error se ensalza como práctica estética y ética

Poiésis, Niterói, v. 20, n. 33, jan./jun. 2019. 


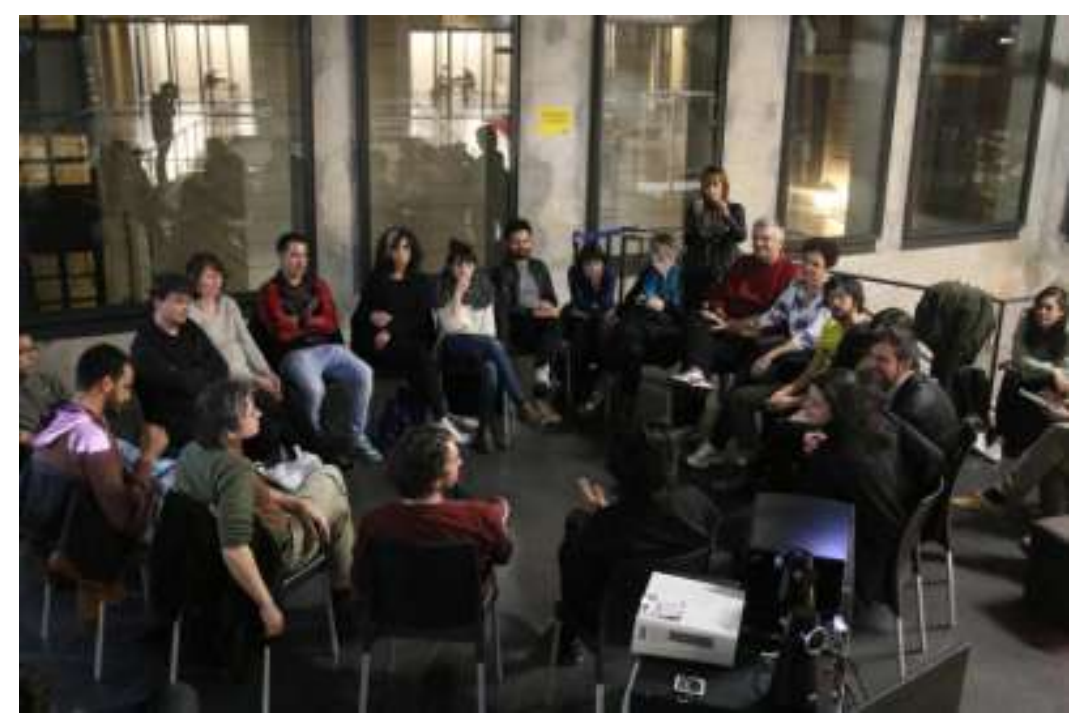

Fig. 6 - Laboratorio Edunoise en MediaLab Prado. Madrid. 2015. (Foto: Eva Morales Gómez) 
- Perder el tiempo es una ley moral

- Los ruidos (humanos, animales, guturales, ambientales, analógicos y digitales) nos harán libres

- Proclamamos la belleza de lo hecho a mano, del juego y del trasteo

- Transformamos la basura, lo roto y lo rompible en juguetes indomesticables

- Lo individual y la comunidad se organizan y reorganizan de manera orgánica, sana y natural

- El amor, el respeto y la curiosidad son la base de nuestra comunidad

- El cuerpo no es un límite físico

- El proceso como único valor

- La diferencia entre magia y tecnología es solo una variable histórica

\section{Referencias}

ABDALA, Nayib; SUÁREZ, Edgard. Bajo la Sombra del Árbol. En el blog: http://nayibabdalaripoll.blogspot.com/2015/01/tejidos-del-pensamiento-corporiedad-y.html.

CAPOTE MATOS, Juan. El Arte Sonoro en el Aula. Tesis de máster en formación del profesorado, Universidad de La Laguna. Islas Canarias. 2012-2013. Disponible en https:// www.academia.edu/8020492/El_Arte_Sonoro_en_el_aula.

EDUNOISE. Disponible en https://cargocollective.com/EduNoise

EXPOSICIONES de la Sala De Experimentación Sonora - Lab3. http://elmamm.org/Exposiciones/Lab3.

SCHULTES y RAFFAUF. El bejuco del alma. Bogotá: El Áncora Editores, 2004.

KAHN, Douglas. Earth Sound Earth. Signal Energies and Earth Magnitude in the Arts. Oakland, CA University of California Press, 2013.

MALOKA WUF, Registros del autor. Disponible en https://www.youtube.com/watch?v= jiWYI-tMRcI; https://www.flickr.com/photos/122004875@N06/13608661603/in/photostream/.

MINKA LAB, entrevista al autor. https://www.youtube.com/watch?v=dWOp9LqbeTw\&t $=240 \mathrm{~s}$.

URBINA RANGEL, Fernando. Diïjoma: el hombre-serpiente-águila: mito Uitoto de la Amazonia. Convenio Andrés Bello, 2004.

Poiésis, Niterói, v. 20, n. 33, jan./jun. 2019. 